April 2017

\title{
Bomb blast in a tertiary care hospital, the challenges faced during management of victims in a resource limited country
}

\author{
Rizwan Sultan \\ Aga Khan University, Rizwan.sultan@aku.edu \\ Hasnain Zafar \\ Aga Khan University, hasnain.zafar@aku.edu \\ Umar B \\ Aga Khan University \\ Khabir Ahmed \\ Aga Khan University, khabir.ahmed@aku.edu
}

Follow this and additional works at: http://ecommons.aku.edu/pakistan_fhs_mc_surg_surg

Part of the Surgery Commons

\section{Recommended Citation}

Sultan, R., Zafar, H., B, U., Ahmed, K. (2017). Bomb blast in a tertiary care hospital, the challenges faced during management of victims in a resource limited country. Trauma, 24(4), 1-5.

Available at: http://ecommons.aku.edu/pakistan_fhs_mc_surg_surg/491 


\title{
Bomb blast in a tertiary care hospital, the challenges faced during management of victims in a resource limited country
}

Trauma

0(0) I-5

(C) The Author(s) 2017

Reprints and permissions: sagepub.co.uk/journalsPermissions.nav DOI: I0.I I77//4604086/7705 I53 journals.sagepub.com/home/tra

SAGE

\author{
Rizwan Sultan, Hasnain Zafar, Umar Bhatti, Rozina Khimani and \\ Khabir Ahmed
}

\begin{abstract}
Introduction: A bomb blast in a hospital results in a many fold increase in the casualties. The affected health care in the region is the next challenge faced by the administration of the city. We discuss the challenges faced after a bomb blast in the civil hospital of Quetta, Pakistan on 8 August 2016.

Methods: A retrospective review of the medical records of patients who were transferred by air to the Aga Khan University Hospital Karachi over a period of $86 \mathrm{~h}$ after the blast in Quetta.

Results: Seventy-five patients were received in three separate waves; those received in the first wave were sicker than the following waves. Errors in triage and communication which could have been prevented were identified.

Conclusion: Security of hospitals needs to be improved to avoid such incidents in future. The teams involved in the management of these incidents should be trained about triage and communication and its importance. There is need for designated trauma centers to take care of these incidents.
\end{abstract}

\section{Keywords}

Bomb blast, tertiary care, developing country, Pakistan

\section{Introduction}

Bomb blast injuries have become common due to the ever increasing acts of terrorism worldwide. ${ }^{1}$ The devastating effects of bomb blast increase significantly when such an incident occurs inside a health care facility, ${ }^{2}$ as besides the large number of civilian casualties, it paralyses the very facility that would otherwise aid the injured. This results in many administrative and logistic hurdles including the timely transfer of these patients to other hospitals for appropriate treatment, which may necessitate long distance transferthese challenges are even more profound in a resource-limited country. The International Institute for Counter-Terrorism estimate that there have been approximately 100 such attacks that target health care facilities, ${ }^{3}$ although the reporting of the healthcare implications thereafter is scarce.

On 8 August 2016, a suicide bomb blast occurred in the emergency department (ED) of a government hospital in Quetta, the provincial capital of Baluchistan, killing 67, leaving more than 100 wounded and rendering the hospital dysfunctional., ${ }^{4,5}$ Initial emergency care was provided at the Military Hospital in Quetta, before air transfer $700 \mathrm{Km}$ in three C-130 flights to the Aga Khan University Hospital (AKUH) in Karachi for definitive care and rehabilitation. This descriptive study examines the challenges encountered by the arrival of large numbers of casualties in this manner in an already busy hospital and discusses how such a process could be improved.

Department of Surgery, Aga Khan University Hospital, Pakistan

Corresponding author:

Rizwan Sultan, Department of Surgery, Aga Khan University Hospital, Stadium Road, Karachi 74800, Pakistan.

Email: imrizwan12@yahoo.com 


\section{Methods}

The medical records and Hospital Information Management System (HIMS) entries of all the casualties transferred to AKUH from Quetta were examined for descriptive data; the authors' views of the administrative challenges presented were also recorded.

\section{Results}

A total of 75 bomb blast victims were received in three waves on successive days at AKUH (28 patients within $14 \mathrm{~h}, 15$ patients $38 \mathrm{~h}$ after the blast, and 32 patients arrived $86 \mathrm{~h}$ after); two were female and there was a mean age of $36.7 \pm 8.75$ years.

\section{Communication}

Although information about the transfer of patients was communicated to the AKUH authorities at least $6 \mathrm{~h}$ before the first patient arrived, this primary communication occurred at city commissioner level and included only the number of casualties without any further medical details. The notice did however allow AKUH to alert and prepare the trauma team, nursing, and operating room (OR) staff, the security and management staff, and receive volunteers offering to provide their services.

\section{Preparation}

The trauma surgeon, orthopedic surgeon, emergency physicians, nursing supervisor, bed management supervisor, and the administrator of the hospital met urgently, prepared a management strategy and distributed tasks. Due to $100 \%$ occupancy of the emergency room beds, the blast victims were accommodated in various hospital wards and elective admissions were temporarily halted in order to make room; in addition, stable patients on the general wards were transferred to the private and semi-private wards. Trauma teams were structured according to the available bed slots, comprising the consultant trauma surgeon, the trauma fellow, the on-call residents, and the interns in charge of the wards. Emergency buckets containing medication, IV fluids, and other relevant equipment were provided to each area where the blast patients were to be admitted. Four ORs were reserved in case any emergency surgical intervention was required.

This was repeated for the two subsequent waves of patients, although managing beds for the third wave became challenging since the hospital was already occupied by the 43 blast victims along with other elective and emergency patients.

\section{Crowd control and security}

Given that a terrorist bomb had been detonated in the ED of a hospital, security was a key concern. The emergency gates $50 \mathrm{~m}$ from the main ED were closed to the general public $2 \mathrm{~h}$ prior to the arrival of patients. Ambulances carrying patients from the airhead dropped them at these gates, from where they were transported to the Triage area on stretchers, accompanied by single attendant. Access to the emergency room was restricted to authorized personnel only. The process was repeated for each wave. Initial crowd control did not prove to be difficult as the patients were shifted from one city to another and most of them were accompanied by a single attendant only. Problems encountered later were due to a heavy influx of patient attendants arriving at the hospital and the special protocols arriving with government officials visiting to meet the blast victims.

\section{Triage}

Based on ISS, patients were triaged into three categories: life threatening injuries, those requiring resuscitation only and those in a stable condition (Table 1). It was planned to take those with life-threatening injuries directly to the OR, but none met the criteria. Patients requiring resuscitation and investigations were planned to be shifted to the General Surgery ward and the patients who were stable or had isolated limb injuries or head injuries were shifted to the Orthopedics and Neurosurgery wards, respectively. A management staff member was assigned to collect data at the triage area.

\section{Initial evaluation and treatment}

Initial evaluation and treatment of patients was done at their bedsides by the team allocated to the area. Three patients received in Wave 1 had CT scans for their abdominal injuries, whereas the others underwent plain radiograph trauma series and a bedside FAST. One patient with $40 \%$ burns was managed in the special

Table I. Result of triage of 75 bomb blast patients at AKUH.

\begin{tabular}{lllll}
\hline & & \multicolumn{2}{c}{ Triage category } \\
\cline { 3 - 5 } & & \multicolumn{4}{c}{$\begin{array}{l}\text { Requiring } \\
\text { resuscitation } \\
\text { Number of }\end{array}$} & $\begin{array}{l}\text { Life } \\
\text { Wave }\end{array}$ & patients & threatening & abdominal injury & patients \\
\hline I & 28 & 0 & 13 & 15 \\
2 & 15 & 0 & 3 & 12 \\
3 & 32 & 0 & 2 & 30 \\
\hline
\end{tabular}


Table 2. Comparison of primary procedure of patients in each wave.

\begin{tabular}{lllll}
\hline Intervention & Wave I & Wave 2 & Wave 3 & Total \\
\hline $\begin{array}{l}\text { Wound debridement } \pm \\
\text { foreign body removal }\end{array}$ & $16(57.14 \%)$ & $5(33.3 \%)$ & $14(40 \%)$ & $35(46.67 \%)$ \\
ORIF & 4 & 0 & 2 & $6(8 \%)$ \\
External fixators & 1 & 1 & 0 & $2(2.6 \%)$ \\
Eye washout & 1 & 0 & 0 & $1(1.3 \%)$ \\
Laparotomy & 0 & 1 & 0 & $1(1.3 \%)$ \\
Craniotomy & 0 & 1 & 0 & $1(1.3 \%)$ \\
Repair of soft tissue & 0 & 1 & 1 & $2(2.6 \%)$ \\
No intervention & $6(21.43 \%)$ & $6(40 \%)$ & $15(42.85 \%)$ & $27(36 \%)$ \\
\hline
\end{tabular}

ORIF: open reduction and internal fixation.

care unit. During Wave 2, two post-operative patients needed an abdominal CT scan and two needed head CTs; no portable investigations were required. None of the Wave 3 patients required investigations. Six laparotomies had been performed in Quetta, with four arriving at AKUH in Wave 2 and one in each of the other two waves.

\section{Operative interventions}

Nearly half $(47 \%)$ of patients required only wound debridement at AKUH and $36 \%$ patients did not require any intervention at all (Table 2). Only one patient required laparotomy and one needed craniotomy for removal of fragments from the brain. The rate of 'no intervention' increased from $21 \%$ in Wave 1 in Wave 2; all patients had their first operative intervention within $24 \mathrm{~h}$ of admission.

\section{Visits by Government officials and other leaders}

The Government representatives and other political and non-political leaders visited the patients the day after the blast, which resulted in crowding in the wards and affected the treatment of the patients.

\section{Discharges}

Patients were discharged once treatment was completed and patients were rehabilitated; the median length of stay was 8 days (IQR 4-11), but five patients were admitted for more than 3 weeks. The patients with minimal or superficial injuries all remained admitted for at least 2 days. There was no mortality.

\section{Disturbances in elective work}

There were significant disturbances in elective work, mainly due to occupancy of the beds by the bomb blast victims with waiting time for elective patients increasing significantly. There were still seven patients waiting for elective admission at $1600 \mathrm{~h} 1$ week after the bomb blast and it took 10 days before there were no elective patients waiting for a bed at $1600 \mathrm{~h}$.

\section{Readmissions}

Five patients were readmitted within 30 days of discharge, two for planned fixation of their limb fractures. Three were readmitted, however, for evisceration of bowel shortly after removal of their skin sutures, as it became evident that closure of the rectus sheath had not been performed at the initial laparotomy at the Civil Hospital, Quetta, and this had not been communicated to the surgical team taking care of these patients at AKUH Karachi.

\section{Discussion}

Bomb blasts within the premises of a health care facility create a health crisis; the provision of health care to those affected is not only demanding with regards to the severity of injuries sustained by the victims, but because the facility itself is left ineffectual due to the damage inflicted by the explosion. Providing emergent care to these patients becomes even more problematical if the bombed hospital is the only facility in a wide geographical area equipped to provide health care to patients on such a scale. Incidents such as this raise concerns about the security of medical centers all over the country and immediate actions at the level of governmental policy-making should be taken that will address the gaps in the security system presently in place at the hospitals and improve the level of training of the security personnel. The bomb blast at the Civil Hospital in Quetta could have been prevented had there been a better check on security. ${ }^{6}$ 
There needs to be a skilled Emergency Medical Services (EMS) team to triage these patients at the site of the incident, ${ }^{7}$ so that those who require emergent medical attention are moved first, which also helps in identifying only those patients for the transit to the hospital who will benefit from medical intervention. None of the patients that AKUH received died and significant proportions $(21 \%$ in Wave 1 and $42 \%$ in Wave 3) required no intervention at all, suggesting that although the more seriously injured were transferred first, many were moved unnecessarily, which could have been avoided by better triage systems at the initial hospital.

There is a need of a proper communication system to inform the nearest health care facility ${ }^{8}$ about the details of the severity of injuries and the condition of the patients before these patients arrive; the primary information was relayed between government officials and the final word that reached the hospital administration lacked the detail that could have helped in organizing a better plan for the patients arriving.

Readmission of the three patients following evisceration through the incision site could have been prevented if the trauma team at AKUH had been alerted that the rectus sheath of these patients was not sutured during the index operations. We understand that it can be challenging to suture the rectus sheath of all these patients owing to shortage of time, but it is pertinent to directly inform the team in charge at the receiving hospital, so that elective procedures can be planned for sheath closure and complications avoided. This kind of communication gap can generate serious issues even in elective transfer of patients between two centers let alone disaster situation. ${ }^{9}$

The AKUH in Karachi serves as the major tertiary care center in the southern part of the country, and provides 64 beds in the emergency room for patients requiring emergent medical attention. There is, however, only a single trauma bay to triage the post-traumatic patients arriving at the hospital from all over the province of Sindh as well as the neighboring province of Baluchistan. The hospital has inadequate resources to deal with such a mass influx of patients, and this is reflected by the disruption to the routine activities of the hospital at times of such emergencies. It also becomes challenging to allocate beds to all the patients arriving at the hospital.

There is now undoubtedly a need to have specialized trauma centers across the country, which should have sufficient beds to receive post-traumatic patients from such disasters. ${ }^{10-12}$ They should be equipped with trained paramedical staff and modern technology to allow the trauma teams to provide proper care to the patients. The government should place due emphasis on establishing these centers in the country, so that the trauma patients can receive prompt medical care when needed. This will not only allow for trauma patients to receive quicker assessment and care, but will limit the disruption to the elective and emergency admissions to a tertiary care hospital such as AKUH. In this case, there was a 10-day delay in accommodating the seven elective patients waiting for hospital admission as all beds were filled by bomb blast victims. Transferring the previously admitted patients to private and semi-private wards in order to make room for bomb blast patients was not only troublesome for the hospital management, but it also posed a great financial burden since the extra charges had to be accounted for by the hospital's own funds.

Security and crowd control are major issues that need to be dealt with in these circumstances. ${ }^{13}$ The security department at the AKUH took prompt measures to ensure that the hospital was secure. Unnecessary crowding within the hospital was prevented by making sure that only one attendant accompanied each patient initially, however, extra attendants arriving with later contingents posed some difficulties with regards to preventing overcrowding at the hospital.

The care of both the trauma patients and the hospital in-patients is hampered by the unannounced and unplanned visits of political and non-political leaders; their visits after such incidents may be essential for nonmedical reasons but they lead to overcrowding and delays in provision of medical care. The hospital authorities should control these matters and prompt the government officials about the ways in which these visits may affect the efficiency of provision of health care to the patients. There also needs to be a close check on the number of security personnel who escort these government officials during their visits.

Appropriate duration of hospital stay is important not only to limit preventable expenditure but also to make sure that the patients are not needlessly exposed to nosocomial infections. During this experience, $50 \%$ of the patients did not require any intervention, yet the mean length of hospital stay was 8 days, with even those who received only superficial injuries being admitted for at least 2 days; no patient, however, contracted a hospital-acquired infection during their stay.

\section{Conclusions}

Hospitals are becoming attractive targets for the terrorists, not only because of easy access but also because of the potential for increased numbers of casualties and the authorities should improve hospital security to prevent such incidents. The government should focus on building dedicated trauma centers across the country coupled with improved in-field triage of the victims to 
ensure best utilization of resources. Transfer of patients should always be accompanied by good and effective communication between the two centers.

\section{Declaration of conflicting interests}

The author(s) declared no potential conflicts of interest with respect to the research, authorship, and/or publication of this article.

\section{Funding}

The author(s) received no financial support for the research, authorship, and/or publication of this article.

\section{Provenance and peer review}

Not commissioned, externally peer reviewed.

\section{References}

1. Khurana P and Dalal PS. Bomb blast injuries. $J$ Punjab Acad Forensic Med Toxicol 2011; 11: 37-39.

2. DePalma RG, Burris DG, Champion HR, et al. Blast injuries. New Engl J Med 2005; 352: 1335-1342.

3. Ganor B. Terrorist attacks against hospitals case studies, https://www.ict.org.il/Article/77/Terrorist-Attacksagainst-Hospitals-Case-Studies (accessed 3 April 2017).

4. Pakistan: dozens dead as bomb hits mourners at Quetta hospital, https://www.theguardian.com/world/2016/aug/ 08/pakistan-dozens-feared-dead-as-bomb-targets-mourners-at-hospital (accessed 3 December 2016).
5. 70 dead as blast hits Quetta Civil Hospital after lawyer's killing, 9 August 2016, http://www.dawn.com/ news/1276183 (accessed 3 December 2016).

6. Kaplan EH, Mintz A and Mishal S. Tactical prevention of suicide bombings in Israel. Interfaces 2006; 36: 553-561.

7. Scott JA, Miller GT, Barry Issenberg S, et al. Skill improvement during emergency response to terrorism training. Prehospital Emerg Care 2006; 10: 507-514.

8. der Heide EA. The importance of evidence-based disaster planning. Ann Emerg Med 2006; 47: 34-49.

9. Greenberg CC, Regenbogen SE, Studdert DM, et al. Patterns of communication breakdowns resulting in injury to surgical patients. J Am Coll Surg 2007; 204: 533-540.

10. Richardson JD. Trauma centers and trauma surgeons: have we become too specialized? $J$ Trauma Acute Care Surg 2000; 48: 1 .

11. Celso B, Tepas J, Langland-Orban B, et al. A systematic review and meta-analysis comparing outcome of severely injured patients treated in trauma centers following the establishment of trauma systems. J Trauma Acute Care Surg 2006; 60: 371-378.

12. Chiara $\mathrm{O}$ and Cimbanassi $\mathrm{S}$. Organized trauma care: does volume matter and do trauma centers save lives? Curr Opin Crit Care 2003; 9: 510-514.

13. Frykberg ER. Medical management of disasters and mass casualties from terrorist bombings: how can we cope? J Trauma Acute Care Surg 2002; 53: 201-212. 